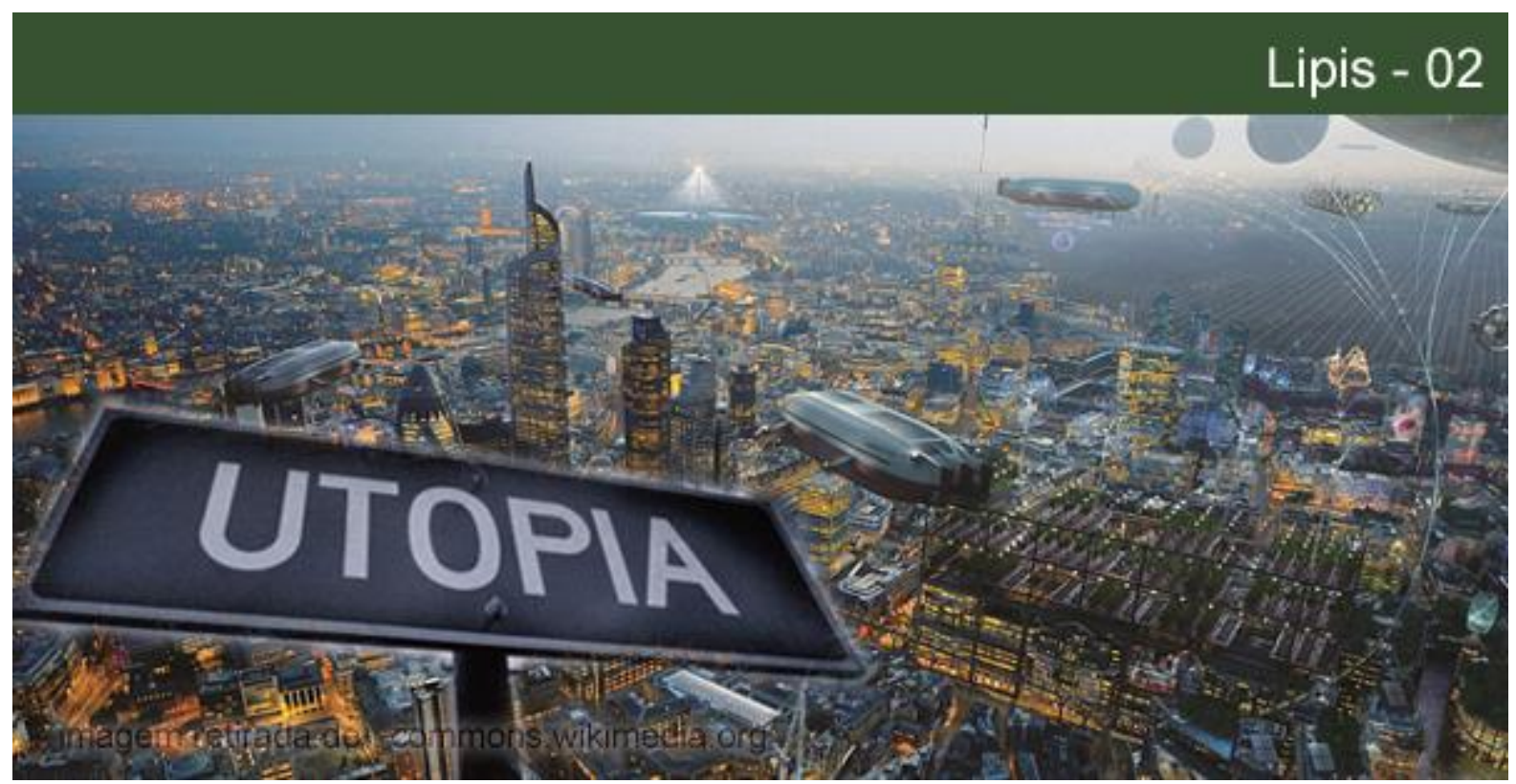

\title{
UTOPIAS E A PARCIALIDADE DA IMAGEM
}

\section{Flademir R. Williges}

Professor de Filosofia do Instituto de Educação, Ciência e Tecnologia do Estado do Rio Grande do Sul. E-mail: flademirroberto@msn.com.

\section{Edson Luiz André de Sousa}

Psicanalista. Professor titular do Departamento de Psicanálise e Psicopatologia da Universidade Federal do Rio Grande do Sul (UFRGS). Professor do PPG Psicanálise: Clinica e Cultura - UFRGS e PPG Psicologia Social-UFRGS. Pesquisador do CNPQ. E-mail: edsonlasousa@uol.com.br.

Resumo: Este ensaio busca desenvolver qual seria a gramática mínima do pensamento utópico, apontando principalmente sua dimensão critica ao que instituímos por progresso. Desenvolvemos também uma série de pressupostos conceituais em torno do conceito de utopia que nos permitirá entender a atualidade desta discussão para as questões de nosso tempo.

Palavras- chave: Utopia. Imagem. Repetição.

\section{UTOPIAS AND THE PARTIALITY OF THE IMAGE}

Abstract: This essay seeks to develop what would be the minimum grammar of utopian thinking, especially pointing his criticism for the progress. We have also developed a number of conceptual assumptions around the concept of utopia that will allow us to understand the relevance of this discussion to the issues of our time.

Keywords: Utopia. Image. Repetition.

“A história das comunidades utópicas é, em geral, um fracasso. [...] Contudo, ignorar o fracasso é errar em relação à história, como se nada de positivo ou humano dela resultasse".

(Russsel Jacoby).

\section{POLÊM!CA | Revista Eletronica da Ueij}


Falar sobre utopia exige que se tenha um conceito mínimo sobre o funcionamento do sistema em que se vive, sobre como consideramos os sujeitos e os objetos de nosso cotidiano, uma vez que estes são deslizantes, são os que mais nos escapam. Além disso, uma imagem desejável de futuro pode ser defendida desde que consideremos que no encontro com o outro há um incalculável que, muitas vezes, nos obriga a mudar o cálculo da vida. Ou seja: no encontro com o outro há diferentes maneiras de se deixar contagiar. Há muitos possíveis, mas nem todos eles são igualmente promissores. Nossos melhores sonhos podem dar em nada, e após tomarmos conhecimento da falência da imagem, gostaríamos mesmo de prescindir de têlos. Mas não há arrependimento para o passado. Por isso mesmo, uma utopia concreta, no sentido pleno da palavra, não reconheceria nem os limites físicos, nem a morte, posto que a imaginação utópica inventa formas que se apresentam como uma contínua perturbação em relação à visão recebida da natureza da realidade e dos artifícios do homo faber. A utopia não pode ser uma imagem meramente sonhada. Para dar um exemplo da força da imaginação utópica, ela quer fritar um ovo numa panela de madeira tendo água como óleo. Por isso, em minha opinião, o problema das utopias não é tanto lidar com o existente instituído e com as imagens dele recebido, consumível, que você sabe como se faz, ou em vias de realização por canais programáveis, e sim com o modo como poderíamos ser menos abstratos, mais imaginativos, mas fantasticamente exatos, o que quer dizer, aqui, mais sensíveis às coisas que acontecem ao nosso redor, e menos ideólogos ou sonhadores abstratos.

O hábito de abstrair, de "tirar" $(a b)$ a força substituindo-a por representações e conceitos é constitutivo do pensamento. Transformar o impacto do sensível imediato em figuração linguística, em metáforas e metonímias, poetizar imagens visuais e acústicas, é um trabalho intelectual de primeira grandeza. Todavia, sua lógica pode amputar partes do objeto e do sujeito a ponto de torná-los irreconhecíveis em sua gênese e historicidade. Também os objetos nos fazem perguntas, se os deixarmos falar. Toda utopia comporta a intuição imaginária da vivência de sujeitos e objetos num arranjo de mundo diferente. Todas propõem construir outra ordem, mas não podem prescindir de uma compreensão de futuro em que tempo e espaço entram em consideração de modo modificado, instaurando como que um universo paralelo, universo este em que, para nosso espanto, muitos artistas convivem. Admiro e mesmo invejo as formas novas que inventam. Todavia, a psicanálise e a filosofia socrática nos ensinam duas coisas fundamentais: não existe objeto algum que tenha o formato 
apropriado para nos tapar a boca - embora continuemos engolindo sapos - e, por outro lado, nem sabemos para onde vamos. Por isso, manter viva a inquietação socrática parece importante, ou seja, perguntar às certezas ou aos que se encontram certos do fim. Isso deveria mitigar a angústia, não fosse o desejo de uma imagem que tapasse todos os orifícios e mostrasse o que tem depois. Bem, depois, nós não sabemos. Voltar a uma forma emocionada de ser, como quem se encontrasse pela primeira vez, isto é a utopia, porque implica a coragem de partir para ilhas desconhecidas, com um mapa escrito numa língua estrangeira. Descerrar as gavetas onde escondemos envergonhadamente nossas precárias poiésis juvenis para virtuais aberturas ao que fomos e recalcamos implica compartilhar uma produção possível. A forma da intuição utópica do espaço e do tempo é crítica à mera funcionalidade social moderna, onde o tempo é vivido como progresso contínuo e os lugares como ocupação total do espaço, mesmo que vazios, à espera especulativa de uma melhor oferta. O cemitério está cheio de melhores ofertas. Escolha seu túmulo. Existem, porém, formas úteis da inutilidade humana de tempo e espaço que podem ser vivenciadas de maneira diferente.

Uma mudança começa, portanto, pela ideia, pelo pensamento, pela quebra do tabu da necessidade do sempre igual. A capacidade de criar imagens de pensamento dissidentes é maior para quem não está tão preso às formas existentes, e pode ocorrer num momento de esgotamento de certa forma de vida de alguém. Todavia, se isso for, em todo caso, um avanço, porque imagina o diferente, deve, porém, depois dele alcançado, vigiar e proteger-se contra a prática da censura e da proibição do pensar, para conservá-lo, pois censurar e proibir é muito mais velho do que o exercício do novo, e a tentação de recuar sempre nos espreita. Pensar exige certa constituição estomacal e mental, porque supõe voltar-se contra si mesmo, contra impulsos imediatos de apropriação, contra as próprias abstrações, como por exemplo, na ideia de que exista um Bem em si incondicionado. Precisamos criar condições de possibilidade para tornar as coisas pensáveis. A virtude da paciência tem sua função. Nascemos no escuro. A Filosofia, a Arte, a Política e a Ciência são múltiplos que se entrecruzam, como diria Alain Badiou, e podem nos dar alegria e prazer, após a busca apaixonada pela resolução de problemas situados em cada uma destas formas de fazer.

É bom lembrar que nunca é tarde para ter novas experiências. Mas para isso, a ideia de uma utopia, de um não-lugar que pode se tornar lugar, não pode ser vivenciada sozinha, porque nossas primeiras experiências significativas foram com algo que veio ao nosso 
encontro, como se mostra nos versos do poema Riqueza, do livro Magma, de João Guimarães Rosa:

Veio ao meu quarto um besouro

De asas verdes e ouro,

E fez do meu quarto uma joalharia...

(GUIMARÃES ROSA, 1997, p.72)

O discurso utópico pode ser dito histérico se reclama e recusa que a disposição das coisas não está bem assim. Ao questionar a gênese desta insatisfação, usa imagens de uma satisfação possível, parcial, mas nunca pode oferecer a segurança de um berço de ouro. A insatisfação é a coisa mais bem distribuída do mundo. É óbvio que, em tempos de anorexia mental, nem todo discurso utópico chega a ser o que diz. Nosso interesse em pensar o objeto utópico é pôr em funcionamento uma dialética entre as imagens positivadas e aquelas que nos são negadas, tanto quanto pensar as antinomias, ou seja, as contradições insolúveis às quais a própria razão nos conduz, ao facilitar as coisas, ao negar a resistência do ar e nos jogar no vácuo, sugerindo que ali sim desenvolveríamos melhor nosso ser. Se não temos como concretizar uma imagem de satisfação impossível, preferimos então falar de um limite crítico à imagem, de sua parcialidade, para não ceder à tentação totalitária como saída desta dialética negativa. Como não imaginamos que seja possível viver sem representação, imagem aqui, neste contexto, está colada ao que pensamos. Fazemos figurações de nossos pensamentos. Não existe o ser do pensamento sem um algo para o qual ele aponta. Um pensamento que não aponta para algo não chega a ser o que ele diz ser.

É possível que a gente possa crescer além da altura em que se está neste momento? Uma vez que "humanidade" é um conceito ainda não realizado, estamos preparados para suportar a imagem que nos oferece o que já somos?

Frente à questão proposta em aula pelo professor Edson Sousa, a saber: que força teria uma imagem para nos relançar na vida? Após muita hesitação, respondo com o que posso agora neste momento: ela deveria, em uma ação, à altura da qual não se está, fazer-nos crescer até ela. Achato aqui os tempos lógicos - ver, compreender e concluir -, para concluir apressadamente: é antes a potencialidade da imagem que deve ser afirmada - poder que pode ser derivado da perda -, do que a certeza do seu resultado, de sua realização prática. Com isso, algumas condições de base para o ato são necessárias como diagnose e terapêutica

\section{POLÊM!CA | Revista Eletronica da veri}


antifilosófica e psicanalítica que pode ser desdobrada como prática cotidiana. A inspiração é nietzschiana, em sua luta por uma imagem mais humana do homem:

1. É preciso despedir-se da imagem de que uma certa espécie, porque dotada de razão, é o centro do universo. É uma dimensão crítica do geocentrismo útil em tempos de globalização porque faz com que ainda tenha sentido habitar esta terra. Apesar de um Copérnico, ainda somos ptolemaicos.

2. É preciso despedir-se da imagem de que a totalidade do mundo estaria organizada em função do nosso querer e agir e de nossa autoconservação individual. É uma dimensão crítica ao egocentrismo, que faz com que o texto que somos seja apenas um texto, e seu sentido não deva ser ampliado a ponto de nos perdermos em infinitas interpretações, pois sempre haverá mais a interpretar. A estratégia aqui não é hermenêutica. É preciso abster-se do excesso de sentido ou de querer essencializar a aparência. Para que algum sentido ainda possa ser criado/produzido, precisamos de um pouco, talvez bastante, vazio. Mas como antes mencionei, a angústia deve ser dosada, uma vez que não há $O$ objeto e nem sabemos para onde vamos.

Suportar estas badaladas no ouvido significa relacionar teoria e práxis na perspectiva da superação do geo-logo-egocentrismo. Para tanto, é preciso coragem. Coragem teórica de pensar contra si mesmo sem abrir mão de si, uma vez que o único instrumento que temos para isso é o próprio intelecto, o mesmo que faz o mundo girar ao nosso redor, ou seja, em torno do nosso intelecto mesmo. Por outro lado, coragem prática para agir contra a imagem de um "si mesmo" completo, também sem abrir mão de si, para não se fazer de idiota e impotente frente ao poder dos outros, quer sejam sujeitos ou objetos. Desta forma, é preciso despedir-se da ideia de que uma imagem possa dar conta da totalidade de uma situação, assim como uma conversa, ou mesmo este texto. Tal princípio norteador da Utopia é denominado por Edson Sousa em meio à constelação de outros princípios que merecem e carecem mais pessoas que se dediquem à pesquisa como "Utopia como fracasso". Assim, a força que uma imagem tem para nos relançar na vida depende estritamente do quanto somos capazes de deixar vir ao nosso encontro e vivenciar imagens - que sempre são complexos ideológicos, políticoafetivos e existenciais - como imagens imperfeitas, imagens parciais, que têm precisamente o 
valor de fantasias que resistem ou mesmo se opõem ao que Adorno (1995, p.76) chama de “desespero objetivo", o tédio, como algo não realizado e de fato irrealizável naquela forma parcial.

Portanto, psicanaliticamente falando, em uma ação, à altura da qual não se está, pode-se crescer até ela se e somente se não confundirmos impossibilidade com impotência, ou seja, se assumirmos a leitura das imagens a partir da condição humana finita, castrada, e não tentarmos equiparar abstratamente pensamento e ação numa imagem de identidade perfeita. Se for verdade, como afirma Heidegger, que ainda não aprendemos a sermos mortais, a palavra poética de Fernando Pessoa serve para nos lembrar do polo da efemeridade humana, análogo ao da imagem, como contraposição à megalomania perene, como oposição à pose moderna que recusa o sensível e o perecível para melhor armar-se e fechar-se em estratégias de autoconservação:

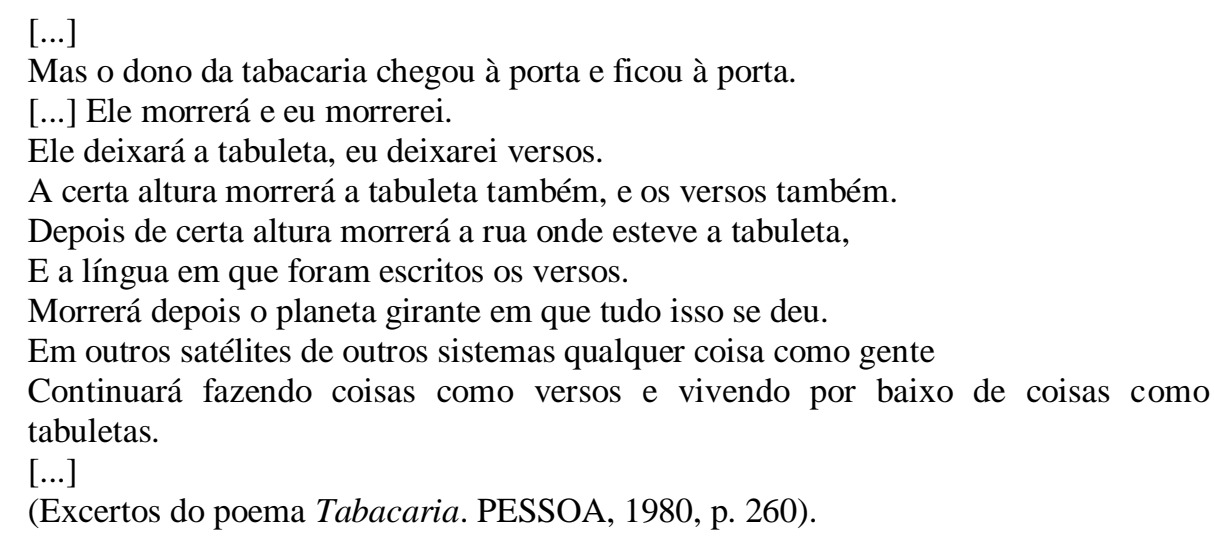

O "não abrir mão de si", perseverar mesmo no insabido da situação, revela a trincheira que podemos construir com o que já temos, ou seja, o MESMO, contra o sempre IGUAL. O mesmo que retorna de nossos fracassos possibilita que a imaginação libertária não se torne presa de uma ideia de concretização que só pensou vitória, e frente ao fracasso, procure incessantemente os responsáveis que a teria desviado do caminho do Bem. A melhor utopia não é a mais perfeita, mas aquela que elucida nossas impossibilidades reais, os limites impostos à vida em sociedade, que concebe os fracassos sociais como responsabilidade coletiva e não culpas individuais, elaborando, em meio aos antagonismos de um poder segregador e racista, um diagnóstico sobre nossa condição de clausura, de desesperança, da inexistência de soluções mágicas.

\section{POLÊM!CA | Revista Eletronica da Uej}


Nunca, porém, o desejo, mesmo que parcialmente realizável, apaga totalmente o fracasso, pois há repetição. Por isso, tanto o saber da história quanto o saber do esquecimento são importantes. Assim, penso que, se o conhecimento não é simples cópia do mundo das coisas como um reflexo no espelho, então, pode ocorrer conceitos aos quais não corresponda nada existente ou nada que possamos imaginar empiricamente. Por exemplo: nada, ninguém, utopos. O mundo dos conceitos, sendo diferente do mundo das coisas, faz com que se possa conceber um tipo de imagem, uma espécie de anti-imagem que não se dissocia, porém, da imagem. É por isso que Arte e Filosofia são irmãs, mas não gêmeas. A função das utopias seria, então, tornar as imagens sensíveis noéticas, isto é, pensáveis, mas não positivadas, e pôr em funcionamento uma das características fundamentais do próprio pensar que é inventar ou dar forma ao não existente, para que não fiquemos totalmente prisioneiros e entregues ao destino cego da natureza ou, em outras palavras, presos diante de portas abertas, apenas encostadas. Assim, como disse uma vez o poeta Lessing: "Quem não perde a cabeça com certas coisas é porque não tem cabeça para perder" (apud FRANKL, 1991, p. 29).

Por outro lado, e para finalizar este ensaio, uma imagem somente tem força para nos relançar na vida se algo em nossa multiplicidade sensível que somos sentir esta necessidade e não deixar escapar, indeterminadamente, a ocasião; se não perder o lance para o relance. Em outras palavras: a gente tem que se imaginar necessariamente forte, senão a gente nunca se torna forte. Mas o forte aqui não é o do senso comum, da doxa. A lição é a de uma crueldade e periculosidade filosófica deixada por Nietzsche, popularizada no dito: "o que não me mata, me fortalece". E, nesta direção, cabe uma crítica àqueles profissionais formadores de imagens, que em nome de uma melhor digestão e resolução instrumental lucrativa de suas produções, eliminam a própria finitude ontológica do ser da imagem, sua potencialidade latente em nos fazer ver os traços da condicionalidade humana, sempre mais envergonhada com a qualidade e limpeza do aparato técnico e tecnológico, que é bom lembrar, não pensa, não sente, não sofre, mas repete maquinalmente. Confundir criação com mera aceitação social ou atualização ao aparato técnico é ratificar um ideal que é mais reativo que ativo, uma vez que não se expõe ao encontro da liberdade, mas busca ser aceito por grupos que querem que a imagem seja mais do que ela é, um meio.

\section{Referência}

\section{POLÊM!CA | Revista Eletronica da Uej}


ADORNO, Theodor W. Palavras e sinais. Petrópolis: Vozes, 1995.

FRANKL, Viktor E. Em busca de sentido. 23a ed. São Leopoldo/Petrópolis: Sinodal/Vozes, 2006. JACOBY, Russel. Imagem Imperfeita. Rio de Janeiro: Civilização Brasileira, 2007.

PESSOA, Fernando. O eu profundo e os outros eus. 16 a ed. Rio de Janeiro: Nova Fronteira, 1980. GUIMARÃES ROSA, João. Magma. Rio de Janeiro: Nova Fronteira, 1997.

Recebido em: 30/09/2015.

Aceito em: 18/11/2015. 